\title{
STUDY ON EFL CLASSROOM MANAGEMENT IN CLASSROOM AT SMP NEGERI 13 AMBON
}

\author{
YULIA SARAH \\ Teacher of State Junior High School 13 Ambon \\ yuliasarahtitaleytoisuta@gmail.com
}

\begin{abstract}
Inclusive classroom is widely discussing around the countries regarding the benefits and the challenges of EFL teachers' constraints in managing the inclusive classroom. This study is aimed at finding out (1) the facts of inclusive classroom management in EFL teaching and learning process, (2) the challenges faced EFL teachers in managing the inclusive classroom and (3) the new insights proposed by EFL teachers for better improvement in managing the inclusive classroom. The findings of the study revealed that; a) Both EFL teachers have clear comprehension about the concepts of classroom management for inclusive classroom but they realized that they didn't optimally implemented the principles of inclusive classroom management. The challenges faced by the EFL teachers in managing inclusive classroom are; a) lack of competencies, b) lack of trainings, c) limitation of teaching and learning facilities based on inclusive students' needs, d) Lack of concrete teaching materials, e) large classes, and f) time allocation. The new insights proposed by EFL teachers can be recommendations for better improvement in managing inclusive classroom in the future.
\end{abstract}

Keywords; EFL teachers, classroom management, inclusive classroom.

\section{Introduction}

Nowadays, many research studies reported the vary findings about inclusive educational practices around the world which are students with disabilities are increasingly educated alongside their non-disabled peers as it pointed out by World Health Organization (2011). Those studies revealed that the growth of inclusive educational practices stems from improved recognition that students with disabilities thrive when they are, to the greatest extent possible the same educational and social opportunities as non-disabled students. In Indonesia context, the inclusive education is arranged by the government and it is written in Permendiknas No. 70 of 2009 that describes the inclusive education is a system of providing education that provides opportunities for all students with disabilities and has the potential intelligence or special talents to attend education or learning in one step of education together with other students. The government has announced that all schools, both public and private, are required to provide special education or provide special services for children with special needs by means of inclusive education. 
In implementing the inclusive education, the government stated the principle of inclusive education is that children with special needs are important to get learning in regular schools, the refusal of children with special needs is violating rights and laws. Educators or teachers will also be provided with insights about education for children with special needs. In implementing the curriculum for inclusive school, teachers need consider the characteristics of students with disabilities, characteristics of subject, the materials, classroom management, teaching strategies, and teaching assessment and evaluation. By considering those aspects, teachers can figure out the strengths and weakness of their teaching practices in covering inclusive classroom. One of the components of curriculum is classroom management, and it is not easy to manage the inclusive classroom. Based on the special case in this school, then the writer is interested to explore more about the ways EFL teachers managing the inclusive classroom. It is interested to dig out the case because in the writer point of view that inclusive education is intended as an education service system that includes children with special needs to learn together with their peers in the regular school closest to their place of residence.

\section{Theory of the Studies}

According to Stainback (2005) 'Inclusive Education as the process of allowing all children the opportunity to fully participate in regular classroom activities regardless of disabilities, race or other characteristics. This shows that education policies that directly or indirectly narrow or bar the chances for certain citizens to acquire knowledge and skills provided in schools due to their racial, gender, religious, socio-economic, regional, or ethnic background are a disaster to education and human empowerment. In Indonesia context, the inclusive education is accordance with the 1945 Constitution article 31 paragraph 1 and Law Number 20 of 2003 about the National Education System which is stated that the state provides full guarantees to children with special needs to obtain quality education services. This shows that children with special needs have the right to get the same opportunities as other children (regular) in education. It means that the state guarantees every child to get their education, without looking at differences.

The needs of inclusive education are crucial to develop equally education, and for that reason, Sunardi and Sunaryo (2011) argued the core concept of inclusive education as it is written in Salamca listing includes; 1) Children have diversity broad in characteristics and their needs. 2) The difference is normal and is present therefore learning must be adapted to the needs of children. 3) Schools need to accommodate all. 4) Children with disabilities should be go to school in the neighborhood his place. 5). Community participation is very important for inclusion. 6) Self-centered teaching children are the essence of inclusion. 7) A flexible curriculum should be adapted to children, not the opposite. 8) Inclusion requires resources and proper support. 9). Inclusion is important for self-esteem human rights and the exercise of human rights humans in full. 10 ) Inclusive schools provide benefits for all children because it helps creating a society that inclusive. 11) Inclusion increases efficiency 
and cost effectiveness of education. 12) Regular school with orientation inclusive is the most way effective for fighting attitudes discriminatory, creates open society, building a society inclusive and achieve education for all. 13) Inclusive schools provide effective education to the majority of children and raising efficiency thereby reducing costs for the whole education system.

\section{Research Methods}

This research used qualitative approach. Data collection techniques were done by using interviews, observation, and documentation. Data analysis techniques were done by analyzing the description, namely through data reduction, data presentation, and drawing conclusions. The study was conducted at SMP Negeri 13 Ambon as categorized as the inclusive school because the school has 14 students with special needs and they are in the first grade. The school is located in Laksdaya Leo Wattimena street, Negeri Lama, Baguala. It is the only one of inclusive junior high school in Nusaniwe district. This school has 609 students, 36 teachers, 27 classroom, 1 department, 46 subjects and 9 subjects for extracurricular activities. For the first grade, there are 6 classrooms with students with special needs.

\section{Discussion}

In the UNESCO document (2013), it is written that teachers have the responsibility to identify and address the barriers in their education system or school that may prevent learners from accessing education, participating in the learning process and making achievements to the best of their individual abilities. Some barriers may include negative parental, family or community attitude towards girl-child education. Similarly, if a teacher has negative attitude about the potential of learners with learning disabilities/ difficulties such as visual and / or hearing impairment, that teacher may not make efforts to include learners with such challenges in classroom activities. Furthermore, barriers to education are often linked to wider structural and cyclical inequalities in the society. For example, members of a poor family may not have access to qualitative education which, in turn, minimizes their chances to power and status in the society.

In gaining the data about the role of classroom management in inclusive classroom, there were 8 questions that have been asked for all the participants covering; 1) What do you understand about classroom management? 2) Do you think that classroom management plays an important role for inclusive classrooms? 3 What are the components in class management for an inclusive class different from the other classes? 4). In which components should be considered in managing an inclusive class, 5) Has the existing classroom management been sufficient to meet the needs of the students? 6) What kind of classroom management do you do in an inclusive classroom? 7). What are the supporting factors in inclusive classroom management? and 8)Are there any inhibiting factors in inclusive classroom management? 
Regarding the first question entitled the concept of classroom management the two English teachers have almost the similar opinions and it was supported with the opinions from counseling teacher and the headmaster as it was shown below;

Pengelolaan kelas adalah cara guru menata kelas yang bukan saja berkaitan dengan bentuk fisik kelas tapi juga cara guru mengelola psikologi siswa untuk tetap termotivasi dalam belajar (T1/FP). + Menurut saya, pengelolaan kelas yaitu guru mengatur dan mengkondisikan ruang kelas dengan sangat baik mulai dari setting kelas sampai kelengkapan sarana pendukung sehingga diharapkan proses pembelajaran dapat berjalan dengan baik (T2/YS). + Menata kelas sesuai dengan karatristik dari mata pelajaran yang diajarkan yang tidak saja berkaitan dengan penataan kondisi fisik kelas tapi juga berkaitan dengan pengelolaan psikologi, emosional dari peserta didik (T3/BK). + Pengelolaan kelas adalah bagaimana cara guru menata kelasnya agar suasana belajar dapat berjalan dengan baik dengan tetap mengutamakan prinsip keadilan dalam kelas inklusif dimana semua siswa diperlakukan secara adil dalam setiap proses pembelajaran (Headmaster)

In term of responding the second question, the responds agreed that the classroom management has an impact in building students' interaction in inclusive classroom as it was presented follows;

Bagi saya sangat berpengaruh karena hal itu berkaitan dengan membangun interaksi yang baik antara siswa dengan guru tapi juga antara siswa dengan siswa. (T1/FP). + Iya, sangat penting. Karena kelas dan seluruh proses terkait dengan pembelajaran diatur dan disesuaikan dengan kebutuhan siswa (T2/YS) Sangat penting, karena karateristik kelas inklusif berbeda dengan kelas regular lainnya. JIka guru tidak memiliki kemampuan mengelola kelas maka akan sangat berpengaruh dengan suasana pembelajaran di kelas (T3/BK). + Bagi saya sangat penting untuk setiap guru pahami dengan baik, karena dengan menata kelas dengan baik bukan saja secara fisik tetapi juga secara non-fisik akan sangat membantu menciptakan suasana belajar yang sehat, aman dan menyenangkan bagi semua siswa yang ada di kelas inklusif (Headmaster)

Item 3 asked about the components of classroom management in inclusive class that different with the regular classroom, all the participants have different opinions as it was explained below.

Saya rasa seharusnya sama cuma ada beberapa pertimbangan yang perlu diperhatikan oleh seorang guru dalam kelas inklusif misalnya daalam penanganan masalah psikologi anak berkebutuhan khusus dalam belajar mungkin perlu dibedakan. Pada dasarnya sama, seperti kurikulum, tenaga pendidik, dan kegiatan pembelajaran akan tetapi proses pembelajaran disetting sesuai dengan kebutuhan siswa.(T2/YS). + Pasti berbeda, karana perlakukan yang diberikan dalam menangani masalah emosi dan sikap siswa juga berbeda (T3/BK). + Seharusya ada perbedaan jika itu berkaitan dengan penataan ruangan, tempat dan fasilitas penunjang pembelajaran di kelas inklusif, namun 
jika dilihat dari penataan kelas yang ada di sekolah ini, masih belum ada perbedaannya, masih sama dengan kelas regular lainnya (headmaster)

As similar in answering item 3, for item 4, all the respondents have different ideas about classroom management as it was explained below.

Saya rasa secara fisik seperti penataan tempat duduk, pencahayaan, mengelola waktu dalam pemberian tugas dan pengunaan metode mengajar yang bervariasi, sementara secara psikologi berkaitan dengan cara mengelola dan menghadapi karakter siswa, pemberian pujian dan hukuman,konsistensi dan control dalam pemberian tugas (T1/FP). + Menurut saya tenaga pendidik seperti guru yang akan mengajar harus memiliki keahlian khusus didalam menangani siswa inklusif, apabila tidak ada maka harus ada kerjasama dengan para ahli atau guru di di sekolah induk (SLB). Proses pembelajaran juga harus di buat dan disesuaikan dengan kebutuhan siswa inklusif. (T2/YS). + Bagi saya yang penting adalah bagaimana seorang guru dapat mengontrol sikap dan tingkah laku dari siswa berkebutuhan khusus sesuai karateristiknya, mampu mengelola emosi jiwanya, dan mmapu membuat dia termotivasi untuk terlibat dalam proses pembelajaran (T3/BK). + Bagi saya ada 2 faktor; dari sisi guru dan dari sisi kelengkapan mengajar untukmenunjang proses pembelajaran. Jika dilihat dari sisi guru berarti berkaitan dengan komptensi guru dalam pengajaran termasuk mengelola kelas, dan dari sisi sarana, harus memfasilitasi kebutuhan belajar dari siswa yang berkebutuhan khusus juga. (Headmaster)

Dealing with the effectiveness of manage the inclusive classroom, the two English teachers agreed that they were not optimally in managing the inclusive classroom because of some factors as it was described as follows.

Mungkin belum terlalu maksimal, namun hasil dari management kelas bisa juga tergambar dari hasil belajar siswa yang cukup baik ketika mereka bisa berpindah ke kelas berikutnya (T1/FP). + Saya rasa belum efektif, dikarenakan ada beberapa hal yang kurang, seperi sarana prasarana yang kurang memadai, seperti kondisi pencahayaan yang belum maksimal sehingga berpengaruh terhadap setting ruangan kelas. (T2/YS).. + Those opinions also supported by the counseling teacher and the headmaster about the effectiveness of classroom management in English teaching process as it was shown below. + Bagi saya sudah cukup effektif, namun tetap perlu pendampingan guru bagi siswa berkebutuhan khusus, kadang saya juga ada di kelas pembelajaran bahasa inggris dan membantu siswa dalam proses pembelajaran untuk konspe-konsep yang sulit (T3/BK). + Saya rasa masih belum effektif, oleh karena berbagai faktor antara lain; kompetensi guru yang berkaitan dengan pendidikan inklusif masih sangat minim serta fasilitas penunjang pembelajaran yang belum lengkap untuk kelas inklusif yang turut memberikan dampak dari cara guru mengelola kelas inklusif.(Headmaster). 
When asking about the principles of managing inclusive classroom all the participants have different opinions based on their experiences in teaching the students in the inclusive classroom as it presented below;

Prinsip-prinsipnya seperti; 1) seorang guru harus bisa menciptakan suasana kelas yang nyaman untuk belajar. 2) seorang guru harus bisa berlaku adil bagi semua siswa dalam hal memberikan kesempatan yang sama untuk semua siswa bisa aktif, 3) seorang guru harus bisa menciptakan interaksi yang baik antar siswa dan siswa, dan 4) seorang harus bisa fleksibel dalam menghadapi siuasi-situasi tak terduga, 5) Mampu mengelola emosi siswa dengan baik dan tepat (T1/FP). + Yang saya ketahui adalah sikap guru yang menganggap perbedaan itu satu, hubungan orangtua dan sekolah, pendampingan pembelajaran dan pembelajaran yang efektif. (T2/YS)

Ya , biasanya jika ada dalam rapat bersama atau juga secara pribadi dengan guru mata pelajaran atau guru kelas, biasanya lebih banyak dengan guru kelas, jika untuk bahasa Inggris mungkin berkaitan dengan membangun prinsip berkomunikasi dan interaksi secara sehat dan benar, itu yang dibagikan supaya gurunya bisa mengembangkannya di dalam proses di kelas. (T3/BK)

Prinsip-prinsip dalam mengelola kelas inklusif yang saya tahu; 1) kemampuan seorang guru dalam memahami karateristik siswa yang berbeda dalam kelas inklusif, 2) kemampuan guru dalam mengakomodasi pembelajaran secara adil dan berkesinambungan bagi semua siswa, 3) kemampuan guru dalam menhadapi berbagai sikap, karakter dan tingkah laku siswa yang berbeda, 4) kemampuan guru untuk dalam menghadapi siswa yang bermasalah di kelas, 5) kemampuan guru dalam menata pembelajaran yang interaktif dan fleksibel dalam menghadapi berbagai situasi pembelajaran di kelas. (Headmaster)

In terms of supporting and constraints factors that influence teachers in managing the inclusive classroom, all the participants almost have the similar ideas below.

Bagi saya faktor pendukungnya adalah berkaitan degan kompetensi pedadogik seorang guru dalam menangani kelas inklusif, harus diperkaya dengan pelatihan-pelatihan khusus untuk pendidikan inklusif serta fasilitas pendukung pembelajaran.

Sudah pasti ada, masih banyak guru yang belum tahu menangani siswa berkebutuhan khusus dengan baik karena jarang mengikuti pelatihanpelatihan yang berkaitan, kemampuan mengembangkan materi ajar untuk siswa berkebutuhan khusus serta pemelihan metode mengajar yang tepat, dan sarana pendukung pembelajaran yang masih minim. (T1/FP)

Fasilitas ruang kelas yang memadai, guru yang memiliki keahlian dalam penanganan siswa inklusif, siswa regular yang saling mendukung dan proses pembelajaran yang disesuaikan dengan kebutuhan siswa inklusif. Faktor penghambatnya bisa saja berkaitan dengan fasilitas yang kurang, guru yang tidak memiliki keahlian inklusif, siswa regular yang memandang perbedaan, 
orangtua yang memperlakukan mereka berbeda sehingga berpengaruh terhadap kepercayaan diri. (T2/YS)

Faktor pendukungnya adalah kemauan dari orangtua untuk melibatkan anak berkebutuhan khusus dalam sekolah regular, yang didukung oleh sikap yang terbuka dari kepala sekolah dan staf guru yang mau menerima tantangan ini, disisi lain perl juga mempertimbangkan banyak faktor untuk keberlanjutan proses pembelajaran yang menyenangkan, sehat dan juga adil bagi semua siswa. Faktor penghambat, tidak semua guru memiliki keahlian dalam mengangani siswa berkebutuhan khsusu., belum semua guru terlibat dalam kegiatan-kegiatan pelatihan untuk sekolah inklusif, dan minimnya fasilitas untuk mendukung proses pembelajaran kelas inklusif. (T3/BK)

Kompetensi guru berkaitan dnegan kompetensi professional dan kompetensi pedagogic, yang didukung dengan kompetensi kepribadian dan social dalam membangun kerjasama yang baik di antara guru kelas dan guru bidang studi, Sarana penunjang dan pendukung pembelajaran yang sesuai dengan karateristik setiap mata pelajaran. Dan faktor penghambat antara lain Kurangnya pengetahuan guru dalam mengembngakan pembelajaran yang inovatif dan interaktif pada kelas inklusif karena kurang adanya pelatihan, Kurangnya sarana belajar yang sesuai dengan karateristik siswa berkebutuhan khusus. (Headmaster)

In managing the classroom, the use of media was also influence the process of teaching and learning in inclusive classroom, and in responding the item 3 related to teaching media. Bothe EFL teachers have the similar commets and it was supported by the counseling teacher and the headmaster as it was presented below.

Ya, saya biasanya pakai media powerpoint untuk memperkenalkan beberapa ungkapan /ekspresi dalam bahasa Inggris atau ketika mengajar tenses, dan juga video atau lagu sesuai dengan materi yang diajarkan (T1/FP)

Ada, saya menggunakan powerpoint dengan tampilan gambar bergerak supaya siswa lebih tertarik atau gambar nyata yang ada didalam kelas supaya bisa langsung dipegang oleh siswa. (T2/YS)

Waktu saya di kelas bersama guru bahasa Inggris, media yang digunakan adalah powerpoint untuk menampilkan konsep-konsep yang diajarkan, kadang juga ada gambar dan lagu sesuai dengan topic yang diajarkan ( T3/BK)

Ya, seperti powerpoint,ada juga dnegan menggunakan gambar, lagu bahkan video pembelajaran (Headmaster)

Regarding the question related to their ways in handling the students who are slowly in comprehending the texts, both teachers have different ways and their comments also supooterd by the Headmaster' comments as follows.

Siswa tersebut diberikan teks yang lebih sederhana, dan mereka juga didampingi tutor sebaya yang akan memandu mereka membaca. (T2/YS)

Kalau aktivitasnya berpasangan biasanya saya tempatkan mereka dengan siswa yang lebih pintar dengan tujuan siswa tersebut akan menjadi tutor bagi 
teman yang berkebutuhan khusus, karena menurut saya merka akan lebih nayman jika belajar dengan teman sebaya. Namun terkadang saya butuh waktu ekstra untuk mendampingi mereka mempelajari materi yang diajarkan setelah pulang sekolah (T1/FP)

Setahu saya biasanya kalau dalam kelas, masih kedapatan kesulitan dalam memahami pembelajaran, maka ada waktu ektra yang diberikan guru untuk les tambahan setelah pulang sekolah bagi beberap siswa berkebutuhan khusus In building students' interaction in inclusive classroom, both teachers mostly preferred to form the students into group my mixing their ability members, as it was explained follows:

Saya rasa melalui aktivitas bekerja secara berpasangan dan bekerja dalam kelompok kecil (4-5 orang) dimana ada kelompok yang terdiri dari siswa yang berkebutuhan khusus dan siswa yang normal. Biasanya saya berikan penjelasan untuk kelompok yang mix dengan berkebutuhan khusus supaya mereka tahu tugas masing-masing (T1/FP)

Mereka saya bebankan tugas, semisal ketua kelompok, sehingga mereka merasa dibutuhkan. Dalam satu kelompok juga terdiri dari 2 siswa inklusif dan 3 siswa reguler sehingga ada komunikasi yang baik antar sesame teman, dengan demikian mereka saling membantu. (T2/YS)

Punishment is also another compenent that always did by the English teachers when they found their students didi't do their tasks, and responding this question, both teachers have different comments as follows;

Saya memberikan tugas tambah, berbeda dengan anak reguler, khusus anak inclusive, saya berikan penambahan waktu untuk dapat menyelesaikan tugas mereka. Berupa tugas tambahan seperti menghafal dialog, sedangkan kalau siswa inclusive diberi penambahan waktu sekitar 1-2 hari untuk dapat menyelesaikannya (T2/YS). + Ya, dan saya rasa itu juga penting bagi siswa untuk bisa belajar bertanggungjawab dengan tugas yang diberikan . Contohnya ketika siswa tidak mengerjakan tugas yang diberikan, maka saya suruh mereka ke perpustakaan untuk membuat tugas mereka sampai selesai, jika itu berkaitan dengan siswa yang berkebutuhan khusus maka saya minta bantuan guru BK untuk memberikan motivasi, setelah itu baru mereka diijinkan untuk mengikuti pelajaran kembali.(T1/FP)

Item 11 asked about the students who did want to be punishement, and responding thisquestion, both teachers have different experiences as it was explained below.

Saya rasa tidak pernah, siswa di kelas inklusif masih tergolong remaja, dan biasanya di sekolah mereka lebih menurut apa kata guru, bagi saya cara kita berbicara dengan lembut dan perhatian kepada mereka akan sangat mempengaruhi karakter siswa di sekolah.(T1/FP). + Pernah, sehingga saya konsultasi dengan walikelas dan membuat laporan ke guru BK kemudian 
dibina, atau orang tua nya di panggil dan diberi arahan terkait sikap siswa tersebut (T2/YS)

In ganing the data about the challenges that EFL teachers have in mangaging the classroom, the respondents were different comments due to some trainings that they ever followed as follows;

Sudah, 1 kali dan saya rasa masih sangat kurang (T2./YS)

Saya rasa pelatihan berkaitan sangat kurang untuk pendidikan inklusif maun untuk kelas inklusif. Selama saya mengajar di sekolah ini belum perah saya mengikuti pelatihan untuk pendidikan /kelas inklusif (T1/FP)

And in responding the question about the challenges on manaing classroom, the comments were shown below;

Tantangannya, banyak siswa yang tidak memperoleh pelajaran bahasa Inggris sejak SD, sehingga saya merasa kesulitan. Karena saya kembali mengulang ke pembelajaran yang paling mendasar. Anak2 merasa kesulitan karena menjadi hal baru bagi mereka dan dibutuhkan bimbingan khusus agar mereka bisa menguasai materi, minimal dari hal yang paling mendasar seperti pengenalan anggota tubuh dll. (T2/YS). + Tantangannya bervariasi, ada yang berkaitan dengan mengelola waktu ketika ada dalam kerja kelompok, maupun ketika ada tambahan waktu untuk mendampingi siswa berkebutuhan khusus sepulang sekolah, pengembangan latihan-latihan dalam pembelajaran bahasa Inggris yang lebih kontekstual khususnya bagi siswa yang berkebutuhan khusus, pengembangan media pembelajaran yang mengakomodasi content siswa berkebutuhan khusus (T1/FP)

For handling those constraints and challenges, the teacher's aslo provided the solution as follows;

Saya rasa pelatihan atau workshop itu penting untuk diikuti utnukmemperkaya wawasan pengetahuan kita khususnya yang berkaitan dengan pendidikan inklusif, dan karateristik kelas inflkusif dalam pembelajaran bahasa Inggris (T1/FP). + Saya menyederhanakan materi ajar yang dapat dimengerti oleh siswa inklusif, menata ruangan kelas seperti tempat duduk dikelas, dan memilih tutor sebaya dari siswa regular yang dapat membantu mereka dalam belajar kelompok. (T2/YS)

Whether for things that needed to be improved for better managening inclusive classroom and any recommendation for the school, they have the similar ideas as follows:

Menurut saya, fasilitas sekolah harus memadai, guru-guru yang akan mengajar di kelas inklusif dibekali dulu dengan berbagai pelatihan, da nada kerjasama dengan para ahli atau sekolah induk SLB (T2/YS). + Diberikan kesempatan untuk mengikuti pelatihan/workshop dan juga penyediaan sarana dan prasarana pendukung pembelajaran. Saya merekomendasikan agar siswa inclusive mendapat perhatian khusus dari semua pihak yang terkait inclusive, sehingga sekolah penyelenggara inclusive benar-benar siap mengahadapi 
tantangan ini. (T2/YS). + Untuk dinas pendidikan; perlu ada program untuk pengembangan sekolah inklusif, ada bantuan dana yang diberikan untuk penyelenggaraan sekolah inklusif, untuk sekolah; perlu ada program untuk kelas inklusif, perlu ada ruangan khusus yang ditata sesuai karateristik kelas inklusif, perlu ada tambahan sarana dan prasarana pendukung, untuk orangtua dan komite : Perlu ada kerjasama dalam mendukung program sekolah khususnya untuk kelas inklusif (T1/FP)

\section{Conclusion}

Based on the findings of the study, some conclusions are determined based on the research questions of this study as follows; The facts of inclusive classroom management of this school covering; a) Both EFL teachers have clear comprehension about the concepts of classroom management for inclusive classroom but they realized that they didn't optimally implement the principles of inclusive classroom management. b) The environment of inclusive classrooms in this school is quite enough to support English teaching and learning process, c) the ways EFL teachers manage the students' behavior are enough optimally in their point of view, that is why they still need assistance from counselor teacher in managing the inclusive classroom, d) in building students' interaction the teachers need to forming group with mix abilities, providing tutor for guiding students' special needs in group work. e) sometimes they still face with inconsistency in implementing rules of classroom management dealing with the routines and rules.

\section{References}

Ainscow, M. (2002) Using research to encourage the development of inclusive practices. In: Ainscow, M. (2009). Psychology for Inclusive Education. New Direction in theory and Practice. London: Routledge.

Ainscow, M. \& Cesar', M. (2006). Inclusive Education, Ten years after Salamanca: Setting the Agenda. European Journal of Psychology of Education. 21 (3) 231-238.

Ajuwon, M.A. (2012). Making inclusive education work in Nigeria: Evaluation of special educators attitudes. Missouri: State University.

Kementerian Pendidikan. (2003). Undang-Undang 20/2003 tentang sistem Pendidikan Nasional Indonesia [Indonesian Government Act No.20/2003

P. Farrell and M. Ainscow (Eds.) Making Special Education Inclusive. London: Fulton.

The Salamanca Statement and Framework for Action on Special Needs Education. Salamanca:

Sunardi \& Sunaryo (2011). Managemen Pendidikan Inklusive. Jassi Anakku, Vol. 10, N0.2 UNESCO \& Ministry Of Education And Science, Spain.

Sunardi \& Sunaryo (2011). Managemen Pendidikan Inklusive. Jassi Anakku, Vol. 10, N0.2 